\title{
A PRESENÇA DE NÃO-ÍNDIOS NAS VILAS DE ÍNDIOS DE PORTO SEGURO: RELAÇÕES INTERÉTNICAS, TERRITÓRIOS MULTICULTURAIS E RECONFIGURAÇÃO DE IDENTIDADE - REFLEXÕES INICIAIS.
}

FRANCISCO CANCELA ${ }^{1}$

$U F B A$

\begin{abstract}
RESUMO: $O$ presente artigo apresenta algumas reflexões sobre os contatos interétnicos entre indios e não-índios nas vilas de indios da Capitania de Porto Seguro, entre os anos de 1758 e 1820. Partindo da identificação dos sujeitos não-indígenas, buscamos apresentar a idéia de que as vilas de indios se transformaram em um território multicultural, onde brancos, mulatos, pardos, negros e indios mantiveram vários contatos condicionados ao contexto geral do processo de conquista e colonização da América portuguesa. Ao mesmo tempo, estas relações possibilitaram uma reconfiguração identitária, uma vez que forjaram experiências de solidariedade, de resistência e de percepção da própria condição em que viviam os índios e os não-índios, principalmente os degredados.
\end{abstract}

PALAVRAS-CHAVES: vilas de indios; relações de contato; Capitania de Porto Seguro; identidade.

ABSTRACT: This article presents some reflections about the interethnic contacts between Indians and non-Indians in the Indians' villages of the Captaincy of Porto Seguro, between the years 1758-1820. Beginning with the identification of the non-aboriginal citizens, we try to show the idea of how the Indians' villages transformed in a multicultural territory, which white, browns, blacks and Indians kept some connections, submitted to the general context of the Portuguese Colonization. At the same time, these connections were allowed to reconfigure the identities, because it put together experiences of solidarity, resistance and perception of the self condition where the Indians and the banished ones lived.

KEYWORDS: Indians' villages, relations of contact, Captaincy of Porto Seguro, identity.

\section{Introdução}

O presente artigo apresenta algumas reflexões sobre os contatos interétnicos entre índios e não-índios nas vilas de índios da Capitania de Porto Seguro (Brasil), entre os anos de 1758 e 1820. Partindo da

\footnotetext{
1 Doutorando em História Social, especialista em Docência, bolsista CAPES - E-mail: franciscocancela@yahoo.com.br.
}

Espaço Ameríndio, Porto Alegre, v. 1, n. 1, p. 42-61, jul./dez. 2007. 
FRANCISCO CANCELA - A presença de não-índios nas vilas de...

identificação dos sujeitos não-indígenas, buscamos apresentar a idéia de que as vilas de índios se transformaram em um território multicultural, onde brancos, mulatos, pardos, negros e índios mantiveram vários contatos condicionados ao contexto geral do processo de conquista e colonização da América portuguesa. Ao mesmo tempo, estas relações possibilitaram uma reconfiguração identitária, uma vez que forjaram experiências de solidariedade, de resistência e de percepção da própria condição em que viviam os índios e os não-índios, principalmente os degredados.

As fontes utilizadas foram, principalmente, as correspondências trocadas entre as autoridades coloniais e as metropolitanas. Além destas, também foram utilizados alguns relatos de viajantes e documentos gerados na administração colonial.

Este trabalho representa uma síntese das primeiras reflexões da pesquisa (em andamento) de doutorado, que estuda as vilas de índios da Capitania de Porto Seguro entre a segunda metade do século XVIII e a primeira metade do XIX. As discussões aqui levantadas representam o resultado do diálogo realizado com as fontes e apresentam novas possibilidades de abordagem da questão indígena, utilizando como ponto de partida as novas proposições historiográficas da chamada "história do contato". Esta nova historiografia possibilitou pensar os espaços coloniais e a história dos povos indígenas de forma mais ampla e diacrônica (SCHWARTZ, 2003; GOMES, 2003; BOCCARA, 2001; MONTERO, 2006).

\section{Contextualizando o surgimento das vilas de índios em Porto Seguro}

As vilas de índios foram criadas no reinado de Dom José I (17501777), que teve na figura de Sebastião José de Carvalho e Melo, o Marquês de Pombal, o representante autêntico da política ilustrada do despotismo esclarecido (FALCON, 1984). Neste período, um estado de instabilidade econômica rondava Portugal, cujas causas estavam na perda da arrecadação tributária nas colônias, no déficit demográfico metropolitano e na crise da produção agrícola. Além disso, no cenário político, a questão da delimitação das fronteiras entre as Américas 
FRANCISCO CANCELA - A presença de não-índios nas vilas de...

espanhola e portuguesa criou certa turbulência institucional. Nestas circunstâncias, mudanças nas estruturas econômica, administrativa e cultural foram necessárias tanto na própria metrópole portuguesa, quanto nos seus domínios de além-mar (ARRUDA, 2001).

Na colônia portuguesa da América, as reformas econômicas mais relevantes foram o fomento à ampliação do comércio e o estímulo à máquina tributária. Do ponto de vista comercial, a criação das Companhias do Pará e Maranhão e de Pernambuco e Paraíba tentou recuperar o controle luso sobre o comércio de exportação e também intensificar o intercâmbio entre metrópole e colônia. Do ponto de vista tributário, a Coroa tentou superar seu déficit, ampliando a cobrança de impostos e radicalizando no combate ao contrabando (FALCON, 2001). A metrópole tentou também ampliar e diversificar a pauta de produção e de exportação, além de racionalizar as técnicas agrícolas usadas, principalmente a expansão produtiva pelo processo de derrubada e queima das matas, que passou a ser bastante criticado por intelectuais da época (PÁDUA, 2004).

As medidas mais importantes que integraram as reformas administrativas sofridas na colônia da América foram: a transferência da sede do Governo Geral do Estado do Brasil, de Salvador para o Rio de Janeiro (1763); a extinção do Estado do Grão-Pará e Maranhão e sua incorporação ao do Brasil (1772) e a incorporação das antigas Capitanias Ilhéus, Porto Seguro e Espírito Santo à da Bahia (1750). Todavia, o mais importante a ser destacado nesta reestruturação do Estado foi a tendência de modernizar política e burocraticamente a administração colonial, entendendo-se como modernização a construção de uma máquina administrativa renovada que desse respostas às exigências conjunturais de Portugal.

A política indigenista não passou incólume a este contexto de crise e reformas. O Marquês de Pombal re-elaborou a legislação indigenista, adaptando-a à conjuntura política, social e econômica do Império Português. Em 6 de junho de 1755, Pombal decretou a liberdade dos índios do Estado do Grão-Pará e Maranhão e de seus bens e comércio, além de incentivar o desenvolvimento agrícola e comercial daquele povo. No dia seguinte, apresentou um Alvará que determinava uma mudança na forma de administração dos índios, retirando poderes civis 
FRANCISCO CANCELA - A presença de não-índios nas vilas de...

e administrativos dos padres regulares e determinando que fossem governados por principais, governadores e pela justiça secular (ALMEIDA, 1997).

Em 3 de maio de 1757, através do diálogo com Francisco Xavier de Mendonça Furtado, governador e capitão-geral do Maranhão e irmão de Pombal, foi publicado o Diretório, que se deve observar nas Povoações dos índios do Pará e Maranhão enquanto Sua Majestade não mandar o contrário (FURTADO, 1758). Este documento tinha como objetivo regulamentar as novas regras de convivência interétnicas apresentadas com as leis de 6 e 7 de junho de 1755. Segundo Mauro Cezar Coelho, a Lei do Diretório

emergiu da necessidade de conciliar dois interesses distintos: por um lado, o metropolitano, o qual pretendia incorporar os índios em sua política de ocupação e defesa do território colonial conquistado aos espanhóis; por outro, o dos colonos, cuja intenção era manter as populações indígenas submetidas, cristalizando a sua condição de mão-de-obra preferencial no Vale Amazônico (COELHO, 2005, p. 246).

Composto por 95 parágrafos, o Diretório apresentava regras de convivência entre brancos e indígenas no Estado do Grão Pará e Maranhão. Dentre as medidas mais importantes, destacam-se: a extensão da vassalagem aos índios; a substituição dos missionários por párocos; a introdução de administradores temporais; a obrigação do uso da Língua Portuguesa; a transformação dos indígenas em pagadores de impostos; o incentivo ao casamento interétnico; a transformação das chefias indígenas em autoridades coloniais e a introdução do governador como mediador na distribuição da mão-de-obra indígena. Todas essas novas experiências se dariam em um novo espaço, pois o Diretório exigia que as antigas aldeias indígenas fossem transformadas em Vilas².

Maria Regina Celestino de Almeida, ao analisar as chamadas reformas pombalinas e seus impactos na vida das populações indígenas, destacou aspectos de ruptura e de continuidade no que tange à política

\footnotetext{
${ }^{2}$ Segundo o Diccionário da Língua Portuguesa, as Vilas eram unidades urbanas menores que as cidades, mas que contavam com juizes, câmaras e pelourinho (SILVA, 1798).
} 
FRANCISCO CANCELA - A presença de não-índios nas vilas de...

indigenista. A partir da comparação entre o Diretório dos Índios de 1757 e o Regimento das Missões de 1686, a autora evidenciou que preocupações como a repartição do trabalho, os cuidados para com as fugas dos índios, a relação com as lideranças indígenas e a necessidade de descimentos eram comuns entre uma e outra legislação. Entretanto, apontou que a "grande diferença estava nos parágrafos relativos aos costumes indígenas, que deveriam ser extirpados, e no forte incentivo à miscigenação e à presença de brancos nas aldeias" (ALMEIDA, 2003, p. 169).

Com a implantação do Diretório dos Índios no Estado do Grão Pará e Maranhão, várias transformações políticas, econômicas e sociais se materializaram no Vale Amazônico. Para Mauro Cezar Coelho, as transformações mais importantes foram: primeiro, a elevação das antigas aldeias missionárias a Vilas e Lugares, que passaram a se constituir na base sócio-econômica da Colônia, pois funcionavam como espaço de arregimentação de mão-de-obra e, também, de socialização e civilização de uma nova sociedade mestiça; a segunda grande transformação foi a de garantir um programa de inserção das populações indígenas na esfera política da colônia, através da cooptação de lideranças, da distribuição de cargos e funções, da nomeação para cargos de chefias e da concessão de honras e privilégios; a terceira, possibilitou a emergência de novas relações sociais a partir do convívio entre brancos e índios num mesmo espaço; por fim, promoveu a emergência de relações diversas entre índios e brancos, que oscilavam da aliança ao conflito e da negociação à adaptação (COELHO, 2005, p. 35).

Através do Alvará de 8 de maio de 1758 , as leis do Diretório se estenderam para toda colônia americana. Com esta medida, o movimento de transformação das aldeias em vilas indígenas se espalhou para toda América portuguesa, permitindo a construção de uma administração civil, a formação de um novo contingente de vassalos indígenas pagadores de impostos e a disponibilidade de mais mão-deobra para os serviços do Estado e dos colonos.

$\mathrm{Na}$ Capitania de Porto Seguro, as vilas de índios foram criadas em dois momentos diferentes. O primeiro aconteceu em 1758 , quando a Coroa portuguesa estendeu as Leis de 1755 para o Estado do Brasil. A 
FRANCISCO CANCELA - A presença de não-índios nas vilas de...

partir deste momento, um conjunto de medidas foi tomado pelo ViceReinado para afastar os padres jesuítas da administração dos aldeamentos e para transformar aqueles antigos núcleos de catequização em novas vilas. Neste contexto, os dois únicos aldeamentos jesuíticos existentes em Porto Seguro, a aldeia São João Batista dos Índios e a aldeia Espírito Santo dos Índios, transformaram-se em vilas, recebendo, respectivamente, a denominação de Vila de Trancoso e Vila Verde (APEB, 603).

O segundo momento começou em 1763, quando o Rei D. José I publicou um Decreto que criava uma nova Ouvidoria na Capitania de Porto Seguro, pautada na máxima de que "sem governo civil não poderão fazer grandes progressos com que desejo beneficiar os vassalos da mesma capitania" (APEB, 7065). Criada sob as inspirações do Marquês de Pombal, a Ouvidoria de Porto Seguro se constituía numa instância jurídico-administrativa mais sofisticada do que a simples organização das capitanias hereditárias, permitindo melhores mecanismos de fiscalização e de centralização de poder. Seus limites geográficos reproduziam a mesma divisão da Capitania, sendo assim desenhado: ao sul fazia fronteira com o Rio Doce - limite extremo com o Espírito Santo; ao norte, com o Rio Jequitinhonha - separando-se de Ilhéus; ao leste, com o Oceano Atlântico; e, ao oeste, com a Capitania de Minas Gerais.

Em 30 de abril de 1763, o Marquês de Pombal elaborou um documento composto de 18 instruções que continha as diretrizes fundamentais para a criação e gestão da nova Ouvidoria. Nos seus aspectos gerais, os objetivos da Ouvidoria estavam baseados numa certa representação de uma sociedade ideal, segundo a qual "sem homens sociáveis e civis não pode[ria] haver Estabelecimento [que fosse] útil" (RIGHB, 1916, p. 63). Assim, para fazer de Porto Seguro um território civilizado, seria necessário converter seus moradores indígenas ao catolicismo, organizá-los política, econômica e juridicamente de acordo com os modelos europeus, transformando-os em produtores inseridos no mercado e em súditos geradores de impostos. Desta forma, entrava em cena o pressuposto da "civilização dos índios de Porto Seguro", caracterizado pela introdução de uma série de mudanças na forma de organização do espaço, no funcionamento da 
FRANCISCO CANCELA - A presença de não-índios nas vilas de...

política e administração dos índios, na estrutura e dinâmica da economia e nas regras de convivência interétnicas.

A instrução de número 17 tratava da necessidade de transformar as Aldeias em Vilas e, também, de estimular o descimento de novos contingentes de índios dos sertões para a fundação de novas vilas, que deveriam adotar nomes de cidades e vilas de Portugal.

17. Ordena também S. Magestade que assim naquellas povoaçoens chamadas Aldeyas que já estão domesticadas, como nas que de novo se estabelecerem com índios descidos; logo que estes se descerem no competente numero, se vão estabelecendo novas Villas e se vão abolindo nellas os bárbaros e antigos nomes que tiverem; e se thes vão impondo alguns outros novos de cidades e villas deste Reino (RIGHB, 1916, p. 63).

Como resultado da ação da nova Ouvidoria foram criadas outras seis vilas de índios em Porto Seguro: Belmonte (1764), São Mateus (1764), Prado (1765), Viçosa (1768), Porto Alegre (1769) e Alcobaça (1772). Nelas, a aplicação dos princípios do Diretório dos índios se constituía em uma obrigação. Por isso, nas vilas de índios de Porto Seguro três fenômenos também se tornaram comuns: a introdução dos índios na administração colonial, a sua transformação em vassalos e tributários do rei e a utilização pedagógica do trabalho sistemático como forma de civilização dos índios.

\section{A presença de não-índios nas vilas de índios de Porto Seguro}

As vilas de índios não eram habitadas exclusivamente pelos indígenas. Diferentemente dos antigos aldeamentos jesuíticos, nestas novas povoações a presença do elemento não-indígena era obrigatória. De acordo com o Diretório dos índios, o contato e a convivência regulares entre os índios e não-índios seria um instrumento eficaz para a civilização dos povos nativos. 0 parágrafo 80 desta lei afirma que

para este virtuoso fim (da civilização dos índios) pode concorrer muito a introdução dos brancos nas ditas povoações, por ter mostrado a experiência que a 
FRANCISCO CANCELA - A presença de não-índios nas vilas de...

odiosa separação entre uns e outros em que até agora se conservam tem sido a origem da incivilidade a que se acham reduzidos; para que os mesmos índios se possam civilizar pelos suavíssimos meios do comércio e da circulação e estas povoações passem a ser não só populosas, mas civis (FURTADO, 1758, p. 34).

Como podemos deduzir, as vilas de índios não eram concebidas como um espaço de simples arregimentação de mão-de-obra, nem tampouco apenas ambiente de catequização coletiva de almas infiéis. Estes novos espaços tinham uma natureza muito mais complexa, pois deveriam funcionar como um território de aprendizado da civilização. E, para tal objetivo, os brancos serviriam de modelos a serem seguidos pelos habitantes indígenas.

Desta forma, os moradores brancos adquiriram um papel fundamental no projeto de conquista e colonização do período pombalino. Os comportamentos sociais dos não-índios deveriam convergir para tarefa de "civilização" dos silvícolas, tanto por meio de determinadas responsabilidades político-administrativas, quanto por meio da exemplar ação cotidiana no trabalho e na religião. Por causa disso, os diretores das vilas de índios deveriam facilitar a entrada de brancos nas povoações, dando-lhes auxílio na construção de suas casas e distribuindo-lhes terras para o cultivo.

A presença de um colono branco em uma vila de índios não poderia representar uma simples "disposição" em morar com os indígenas. Segundo os objetivos traçados pela nova política indigenista, - colono precisava ter consciência do seu papel na tentativa de transformação cultural dos povos nativos. Por isso, o Diretório dos Índios regulamentava a presença do elemento branco nas povoações, impondo-Ihe as seguintes condições: 1 . não ocupar terras dos índios; 2. conservar a paz e a concórdia nas relações estabelecidas para com os índios, reconhecendo neles a "razão genérica de vassalos" do Rei de Portugal; 3. utilizar como critério para distribuição de cargos políticoadministrativos a capacidade individual, impedindo que a discriminação étnica afastasse os índios do governo das povoações; 4. não abandonar o trabalho agrícola para servir de exemplo aos índios; 5. estar ciente que o descumprimento destas condições resultaria na expulsão do colono da vila de índio. 
FRANCISCO CANCELA - A presença de não-índios nas vilas de...

Os moradores não-índios marcaram presença nas vilas de índios da Capitania de Porto Seguro. Embora não tenhamos encontrado nenhum censo que tivesse registrado o percentual exato desta presença, o confronto de várias fontes possibilitou encontrar evidências sobre a existência de habitantes não-índios nas vilas analisadas.

Em alguns casos foi possível a reconstrução parcial da trajetória de vida destes colonos; em outros, apenas o simples registro da sua origem e residência em determinada vila. De qualquer sorte, o conjunto das informações obtidas é suficiente para observar que estes colonos migraram de regiões distintas do Império português em busca de realizações sociais e econômicas e, de forma direta ou indireta, acabaram compondo o quadro das relações do processo de conquista e colonização da América portuguesa.

$\mathrm{Na}$ vila de Alcobaça destacamos três moradores brancos que tiveram origem migracional bastante diferenciada. $O$ primeiro era natural de Valença do Minho, no Reino, e se chamava Bernardo José Correia de Melo. Este colono chegou a assumir o cargo de juiz ordinário da vila, mas se desentendeu com o Ouvidor José Dantas Coelho por causa de disputas ferrenhas na administração da mão-de-obra indígena. O outro era natural da Ilha de São Miguel, principal ilha do Arquipélago dos Açores, palco de inúmeras experiências de colonização portuguesa, tais como o sistema de capitanias hereditárias e as primeiras tentativas do cultivo da cana-de-açúcar. Este se chamava João José Medeiro e, além de também ter servido como juiz ordinário, se destacou na plantação de mandioca, tendo declarado que vivia "de suas lavouras". O terceiro era natural da Ilha de Santa Catarina, na própria América portuguesa, e logo que chegou à Alcobaça assumiu um cargo político na administração da vila, sendo juiz por três anos (AHU, doc. 26335).

Em vila Viçosa a presença de brancos cresceu à medida que se fortaleceu o comércio de farinha de mandioca. Do porto da vila saiam pequenas e médias embarcações que levavam cargas de farinha tanto para os armazéns de Caravelas quanto para outros portos ao longo da costa. A instalação de alguns moradores brancos nesta vila de índios esteve relacionada ao avanço do processo de colonização da região, principalmente por meio da lavoura de mandioca e do comércio da 
FRANCISCO CANCELA - A presença de não-índios nas vilas de...

farinha. Este foi o caso de dois indivíduos: um alemão de nome incerto e o Sr. Bernardo da Mota. O primeiro tinha como profissão a construção naval, sendo responsável pelo fabrico das principais embarcações da vila. O segundo possuía fazenda de mandioca e tinha várias embarcações empregadas na exportação de farinha, o que fazia dele um dos homens "mais ricos e importantes" de vila Viçosa (WIED, 1989, p. 202).

$\mathrm{Na}$ vila de Trancoso pudemos encontrar um fato singular: a dificuldade em assegurar que moradores brancos permanecessem na povoação. Esta situação pode ser identificada na trajetória de dois colonos: o Alferes Venceslau Borges da Trindade e o lavrador João Xavier de Arruda. O primeiro serviu por treze anos seguidos na governança de Trancoso, tanto ocupando cargos militares, quanto cargos civis. O segundo, por sua vez, viveu dezoito anos nesta vila de índio, tendo ocupado até o cargo de escrivão. Ambos, apesar de terem vivido grande parte de suas vidas em Trancoso, resolveram se mudar para a vila de Porto Seguro, onde passaram a servir na sua administração (AHU, doc. 26334).

Alguns fatores específicos podem ter contribuído para a desistência destes moradores de viverem entre os índios de Trancoso. Primeiro, a ausência de uma atividade econômica suficientemente forte na vila, capaz de assegurar expansão de negócios agrários ou extrativos. Segundo, o fato de Trancoso possuir um contingente demográfico muito reduzido, não sendo possível a instalação de grandes investimentos no seu termo. Terceiro, por ter se originado de um antigo aldeamento jesuítico do século XVI, a maioria absoluta dos moradores da vila era de índio, excetuando-se Diretor, pároco e alguns membros do poder colonial. Apesar destas considerações, não podemos negar que o comportamento dos dois colonos retrata uma situação bastante comum nas vilas de índios: a ausência de disposição de moradores brancos para viverem em povoação indígenas, principalmente quando as vilas não tinham atrações econômicas e quando os colonos eram obrigados a assumir cargos de pouca rentabilidade, como os de juiz ou vereador.

Na Capitania de Porto Seguro esta dificuldade em arregimentar colonos dispostos a se instalarem em novas povoações indígenas foi 
FRANCISCO CANCELA - A presença de não-índios nas vilas de...

percebida pela primeira vez pelo Ouvidor Tomé Couceiro de Abreu no ano de 1764. Segundo sua avaliação, a criação de mais vilas de índios somente seria possível com a conjunção de dois fatores: o descimento de mais povos indígenas do interior e a migração de mais colonos ${ }^{3}$. Mas, como estes dois métodos eram onerosos para a Coroa, o Ouvidor informou ao Rei que havia "recomendado ao Chanceler da Bahia que encaminhasse para esta Capitania os degredados que não fossem por ladrões" (AHU, doc. 6430). Desta forma, construiu-se uma alternativa ao povoamento da Capitania: a utilização de degredados ${ }^{4}$.

Tomé Couceiro de Abreu, em quatro anos de governo da Capitania, conseguiu reformar as vilas de Trancoso e Verde, criadas em 1759, e fundou duas novas vilas: Belmonte e Prado. Entretanto, em nenhuma delas foi preciso utilizar a proposta de povoamento por meio de degredados, pois se aproveitou do disperso contingente de colonos e índios mansos que havia nas duas regiões.

Após a gestão de Tomé Couceiro (1764-1767), chegou à Porto Seguro o bacharel José Xavier Machado Monteiro, 1767, para assumir a tarefa de consolidação do projeto pombalino na Capitania, devendo aplicar as mesmas instruções encaminhadas ao seu antecessor. Ao continuar a criação das vilas de índios, o segundo Ouvidor se esbarrou numa grande dificuldade: de um lado, os índios mansos não estavam "descendo no número ponderável"; do outro, poucos colonos brancos se disponibilizavam a ir morar nas novas povoações. Desta forma, nos primeiros anos de seu governo somente foi possível a criação de uma nova vila, aproveitando-se dos habitantes brancos e indígenas que já

\footnotetext{
${ }^{3} \mathrm{O}$ descimento consistia na prática de deslocamento de comunidades indígenas (totais ou parciais) de suas aldeias de origem para povoações coloniais. O ato de "descer" índios do interior do continente para os territórios portugueses esteve presente na colonização portuguesa da América desde o século XVI. Para "persuadir" os povos indígenas a praticarem o descimento, colonos, jesuítas e administradores coloniais prometiam melhores condições de vida, liberdade, terra e instrumentos de trabalho (PERRONEMOISÉS, 1992).

${ }^{4} \mathrm{O}$ degredo era uma condenação judicial que esteve presente na legislação portuguesa desde o século XIV. Consistia em extraditar um criminoso ou delituoso para regiões distante do local do crime ou delito, por tempo que variava de acordo com a gravidade do ato cometido (meses, anos ou para sempre). Na prática, o degredo foi uma ferramenta flexível que permitia a (re)utilização de reservas humanas para a colonização dos territórios portugueses (tanto coloniais quanto metropolitanos), atuando como uma forma de castigo aos indivíduos que cometeram algum crime ou delito e, ao mesmo tempo, como uma possibilidade de regeneração ou purificação comportamental. Na caso da Capitania de Porto Seguro, os degredados utilizados no período em questão vieram da própria América Portuguesa, sendo, portanto, resultado de degredo interno (PONTAROLO, 2007).
} 
FRANCISCO CANCELA - A presença de não-índios nas vilas de...

conviviam no terreno que se transformou em Vila Viçosa (AHU, doc. 7972).

Diante desta dificuldade, José Xavier Machado Monteiro resolveu resgatar a proposta de seu antecessor e passou a cobrar da Coroa portuguesa o envio regular de degredados para o povoamento de futuras vilas em Porto Seguro. Segundo sua argumentação, a Cidade da Bahia (Salvador) não estava cumprindo a lei de polícia, permitindo que inúmeros ociosos e vadios perambulassem pelas suas ruas e recôncavo, fazendo, inclusive, aumentar extraordinariamente o preço da farinha. Defendia, portanto, que estes indivíduos fossem enviados para Porto Seguro para "lavrar onde tanto se pode produzir" (AHU, doc. 8215).

Infelizmente, não pudemos identificar quantos degredados foram enviados para as vilas de índios de Porto Seguro. As fontes que retratam este transporte de vadios e ociosos estão dispersas nas centenas de correspondências realizadas entre o Ouvidor de Porto Seguro e os Governadores da Bahia, em Salvador, e do Vice-Reino, no Rio de Janeiro. Além de não estarem catalogadas pelo seu conteúdo, estas cartas estão espalhadas em dois arquivos bastante distintos e distantes: o Arquivo Público do Estado da Bahia (seção Correspondências recebidas) e Arquivo Nacional do Rio de Janeiro (Inventário Marquês de Lavradio).

Através da leitura de algumas dezenas dessas cartas, conseguimos algumas informações importantes. Os principais portos de exportação de degredados eram o de Salvador e o do Rio de Janeiro. Da Cidade da Bahia vinha pouco mais que meia dúzia por ano e do Rio de Janeiro em menor número por causa da ausência de navegação regular. Segundo José Xavier Monteiro, a qualidade destes degredados era imprópria para a tarefa de povoamento e convívio com os índios. $\mathrm{Na}$ carta de 10 de maio de 1771, os degradados foram tratados como "homens comumente viciosos, que só se lembram ou de fugirem ou de perturbarem aos outros" e que, por isso, "mais mereceriam ir para a forca" (AHU, doc. 8446).

Afinal, quem eram estes "vadios e ociosos" que "pela lei da polícia" tinham que ser transportados de Salvador ou do Rio de Janeiro para viverem com os índios em Porto Seguro? Que tipo de comportamento habitual realizavam no seu local de origem? Qual era a sua etnia e condição sócio-econômica? 
FRANCISCO CANCELA - A presença de não-índios nas vilas de...

Algumas destas respostas foram alcançadas nas correspondências entre o Ouvidor José Monteiro e o Marquês de Lavradio. $O$ anexo 1 revela o perfil comportamental de sete indivíduos que foram degredados durante o ano de 1776. Os crimes que cometeram podem ser encaixados em três modalidades: primeiro, desvios religiosos (curandeirismo e feitiçaria); segundo, desobediência civil (desordem); e, terceiro, atentado à tradição (trajes inadequados). Outra evidência interessante é a identificação étnica dos degradados. Entre os enviados havia duas negras, uma parda e outros cinco com etnia não declarada que, seguindo a regra dos documentos coloniais, têm grande chance de serem brancos. Por fim, a maioria absoluta era feminina, sendo um único degredado homem.

A amostra utilizada não possibilita apresentar conclusões estatísticas definitivas, nem universais. Além de serem dispersos e sem regularidades, os dados que compõe esta tabela retratam apenas algumas remessas feitas da Cidade do Rio de Janeiro, de onde foram extraditados poucos degredados. Entretanto, mesmo nestas condições, a tabela permite deduzir alguns indícios interessantes.

Em primeiro lugar, fica evidente que os degredados que foram enviados para Porto Seguro apresentavam características étnicas e sociais bastante diversificadas. Entre eles havia brancos, mulatos, pardos e negros. Além disso, esses indivíduos tinham trajetórias de vida distintas, sendo alguns deles até ex-escravos. Desta forma, podemos concluir que a presença de degredados nas vilas de índios de Porto Seguro possibilitou a formação de um cenário multiétnico, uma vez que, para além de brancos, outros indivíduos "de cor" compunham também a categoria de degredados ${ }^{5}$.

Em segundo lugar, a insistente presença de detalhamento dos perfis comportamentais dos degredados denuncia a intenção das autoridades coloniais de vigiar e de investir na regeneração dos "vadios e ociosos". Assim, as vilas de índios também seriam utilizadas como território de aprendizagem da civilização para estes indivíduos.

\footnotetext{
${ }^{5}$ Sendo assim, daqui por diante quando falarmos em degredado estaremos nos referindo a uma categoria ampla e diversificada, que era composta, em geral, por indivíduos que cometeram algum delito ou crime nas cidades de Salvador ou Rio de Janeiro e sofreram como penalidade a extradição para a Capitania de Porto Seguro. Estes degredados poderiam ser brancos, mulatos, pardos ou negros.
} 
FRANCISCO CANCELA - A presença de não-índios nas vilas de...

Ainda precisamos responder se os degredados se submeteram às regras de convivência imposta pelo Diretório dos Índios e que tipo de relação foi construída entre os degredados e os indígenas. Para elucidarmos estes problemas faremos uma leitura "à contrapelo" das correspondências dos Ouvidores, buscando responder às seguintes questões: quais as posturas ou comportamentos mais recomendados aos degredados? O que os degredados praticavam em Porto Seguro? E, finalmente, de que forma os degredados interagiam com os índios?

Transferidos para atuarem no povoamento da extensa Capitania de Porto Seguro, os degredados recebiam recomendações incisivas de como deveriam se comportar na nova localidade. Em 1776, o Marquês de Lavradio informava ao Ouvidor de Porto Seguro que todos os degredados que havia remetido àquela Capitania deveriam ser distribuídos pelas vilas mais necessitadas de povoadores e deveriam assumir a tarefa de "cuidar da cultura das terras, plantando as suas lavouras para haver abundância de mantimentos, especialmente de farinhas" (ANRJ, microfilme 024.94). Desta forma, ao assumir a condição de colonos, os degredados tinham direito a receberem pequenos lotes de terra e obrigações explícitas de plantar, cultivar e comercializar determinados produtos.

A natureza desta recomendação se assemelha bastante à quarta condição imposta pelo Diretório dos Índios aos moradores brancos das vilas de índios. De acordo com esta lei, a obrigatoriedade do cultivo da terra pelas próprias mãos serviria de instrumento para animar os índios à sedentarização e ao trabalho agrícola mercantil. A partir do conteúdo da carta do Marquês de Lavradio, parece que os degredados também estavam condicionados ao cumprimento desta obrigação.

A existência de casamentos interétnicos envolvendo degredados também corrobora para a argumentação de que estes estavam submetidos às regras do Diretório. Em várias correspondências do Ouvidor José Xavier Machado Monteiro pudemos identificar que os degredados solteiros eram estimulados a se casarem com as índias, e vice-versa. Em 1775, chegou ao conhecimento do Rei de Portugal que algumas índias já estavam se casando com os não-índios, fato que contribuiria para a conservação da paz e da concórdia entre os habitantes das vilas de índios. 
FRANCISCO CANCELA - A presença de não-índios nas vilas de...

Com estes dois exemplos, acreditamos que os degredados também deveriam, teoricamente, cumprir as cinco condições impostas pelo Diretório dos Índios aos moradores não-índios das vilas. Entretanto, como garantir esta disposição com indivíduos classificados como "vadios e ociosos"? Os degredados pardos e negros forros também seriam encarados como "modelos" a serem seguidos?

Infelizmente, estas perguntas não podem ser respondidas pela ausência de fontes. Apenas podemos indicar que os degredados não corresponderam à expectativa de serem instrumentos para a civilização dos índios.

Para tanto, dois fatos serão tomados como exemplo. O primeiro se refere à postura dos degredados frente ao trabalho. A classificação de "vadios e ociosos" não era um produto desligado da realidade. As reclamações estavam ligadas ao desprezo que muitos dos degredados tinham ao trabalho regular. Certa vez, irritado e desiludido com o papel dos degredados, José Xavier Monteiro disse que eram "gente em todo sentido perversa e na ociosidade muito pior que os índios" (AHU, doc. 9147).

O outro fato se refere às relações estabelecidas entre estes "ociosos e vadios" e os povos indígenas. Além de serem maus exemplos para os índios no quesito trabalho, os degredados acabaram se transformando em aliados nas constantes fugas das vilas de índios. Segundo consta na ata da Câmara da vila de Porto Alegre, todas as vilas de índios de Porto Seguro estavam em estado de alerta, pois "delas fugiam vários moradores, principalmente, índios e degredados: uns para a dos Ilhéus e outros para a do Espírito Santo; uns por mar e outros por terra". De acordo com os vereadores, a causa das fugas advinha de "várias pessoas que lhes davam conselho, favor e ajuda" e que "muitas vezes praticavam em canoas e para isso furtavam outros móveis e bens em que muito danificavam os moradores" (APEB, 485-3).

A construção de alianças entre os indígenas e os degredados deve ser entendida como uma decorrência da própria situação colonial. Em primeiro lugar, índios e degredados foram forçados a viverem em um mesmo espaço geográfico - as vilas de índios -, onde foram submetidos a regras de convivências impostas pela sociedade colonizadora que objetivava molda-los a determinados comportamentos classificados 
FRANCISCO CANCELA - A presença de não-índios nas vilas de...

como civilizados. Em segundo lugar, ambos os segmentos foram utilizados pela sociedade envolvente como mão-de-obra para expansão da economia colonial, fazendo que estivessem presentes nas lavouras de mandiocas e nos portos do comércio de farinha. Sendo assim, a solidariedade mútua e a ação resistente conjunta de índios e degredados revela a consciência dos dois grupos da condição colonial em que viviam. Além disso, essas relações revelam um processo de reconfiguração de identidades a partir das experiências de contato sociais e culturais entre grupos de índios (das mais diversas etnias) e de degredados (tanto branco, mulato, pardo ou negro).

\section{Considerações finais}

As vilas de índios de Porto Seguro eram habitadas, portanto, por moradores de diversas origens étnicas, sociais e econômicas. Este complexo populacional permitiu a construção de relações interétnicas e interculturais bastante diversificadas, uma vez que cada grupo depositava expectativas distintas frente ao projeto de colonização. Entre os não-indígenas destacavam-se os colonos brancos e os degredados, que representavam uma gama plural de indivíduos com perfis e etnias variadas. A interação entre estes não-índios com os indígenas deslizou desde a corroboração à concretização da conquista colonial até a incitação à fuga como forma de questionamento à condição colonial. Sendo assim, a presença dos não-índios, em sua diversidade peculiar, contribuiu para forjar uma identidade própria e inovadora para os índios das vilas de Porto Seguro.

\section{Referências bibliográficas}

ALMEIDA, Maria Regina Celestino. Metamorfoses Indígenas: cultura e identidade nos aldeamentos indígenas do Rio de Janeiro. Rio de Janeiro: Arquivo Nacional, 2003.

ALMEIDA, Rita Heloísa de. O Diretório dos Índios: um projeto de civilização no Brasil do século XVIII. Brasília: Editora Universidade de Brasília, 1997. 
FRANCISCO CANCELA - A presença de não-índios nas vilas de...

ARRUDA, José Jobson de Andrade. O sentido da Colônia: revisitando a crise do antigo sistema colonial no Brasil. In: TENGARRINHA, José (Org.). História de Portugal. revisão técnica Maria Helena Ribeiro Cunha. 2. ed. ver. e ampl. Bauru, SP: EDUSC; São Paulo, SP: UNESP; Portugal, PT: Instituto Camões, 2001, p. 245-263.

BOCCARA, Guillaume. Antropologia diacronica: dinâmicas culturales, procesos históricos, y poder político. In: Nuevo Mundo, Mundos Nuevos. Paris: CERMA, 2001.

COELHO, Mauro Cezar. Do sertão para o mar: um estudo sobre a experiência portuguesa na América, a partir da Colônia: o caso do Diretório dos Índios (1751-1798). Tese (Doutorado em História Social), São Paulo: USP, 2005.

FALCON, Francisco José Calazans. A época pombalina. São Paulo: Ática, 1982.

Pombal e o Brasil. In: TENGARRINHA, José (Org.). História de Portugal. revisão técnica Maria Helena Ribeiro Cunha. 2. ed. ver. e ampl. Bauru, SP: EDUSC; São Paulo, SP: UNESP; Portugal, PT: Instituto Camões, 2001, p. 227-243.

FURTADO, Francisco Xavier de Mendonça. Directório que se deve observar nas povoações dos índios do Pará, e Maranhão enquanto Sua Majestade não mandar o contrário. Lisboa: Oficina de Miguel Rodrigues, 1758.

GOMES, Flávio. Indígenas, mocambeiros e identidades transétnicas nas florestas do Brasil-Guiana Holandesa, séculos XIX - XX. Estudos de História, Franca, v. 10, n. 2, p. 11-42, 2003.

INSTRUÇÕES dadas pelo Marques de Pombal a Thomé Couceiro de Abreu, quando mandou por este magistrado criar a Ouvidoria de Porto Seguro. Revista do Instituto Geográfico e Histórico da Bahia, Salvador, v. 42, p. 63-68, 1916.

MONTERO, Paula (Org.). Deus na aldeia: missionários, índios e mediação cultural. São Paulo: Globo, 2006.

PÁDUA, José Augusto. Um sopro de destruição: pensamento político e crítica ambiental no Brasil escravista, 1786-1888. 2. ed. Rio de Janeiro: Jorge Zahar Ed., 2004.

PERRONE-MOISÉS, Beatriz. Índios Livres e Índios Escravos: princípios da legislação indigenista do período colonial (séculos XVI a XVIII). In: CUNHA, Manuela (Org.). História dos Índios no Brasil. São Paulo: Cia das Letras, 1992.

PONTAROLO, Fábio. Degredo interno e incorporação no Brasil meridional: trajetórias de degredados em Guarapuava, século XIX. Dissertação (Mestrado em História Social), Curitiba: UFPR, 2007.

SCHWARTZ, Stuart. Tapanhuns, negros da terra e curibocas: causas comuns e confrontos entre negros e indígenas. Afro-Ásia, Salvador, v. 29-30, p. 13-40, 2003. 
FRANCISCO CANCELA - A presença de não-índios nas vilas de...

SILVA, Antonio Moraes da. Diccionario da Língua Portuguesa. Composto pelo padre D. Rafael Bluteau, reformado e accrescentado por Antonio de Moraes Silva. Lisboa: Officina de Simão Thadeo Ferreira, 1798.

WIED, Maximiliano. Viagem ao Brasil. Belo Horizonte: Itatiaia; São Paulo: Editora da Universidade de São Paulo, 1989.

Fontes

Arquivo Histórico Ultramarino - Projeto Resgate (AHU)

AHU - Projeto Resgate. Auto de inquirição de testemunhas a que procedeu o juiz ordinário da Vila de Alcobaça, Pedro Antunes Guerra, para averiguações dos progressos da civilização dos índios. Vila de Alcobaça, 18 de outubro de 1803 - doc. 26335.

AHU - Projeto Resgate. Carta do mesmo Ouvidor, dirigida ao Rei, na qual dá importantes informações, especialmente sobre a ereção da Vila Viçosa. Porto Seguro, 24 de fevereiro de 1769 - doc. 7972.

AHU - Projeto Resgate. Relação sobre as vilas e rios da Capitania de Porto Seguro, pelo Ouvidor Tomé Couceiro de Abreu. Porto Seguro, 8 de janeiro de 1764 - doc. 6430 .

AHU - Projeto Resgate. Auto da inquirição de testemunhas a que procedeu o Ouvidor interino e Sargento-mor Francisco Dantas Barbosa, para se informar do estado e civilização dos índios. Porto Seguro, 19 de setembro de 1803 - doc. 26334.

AHU - Projeto Resgate. Carta do Desembargador Ouvidor de Porto Seguro José Xavier machado Monteiro, na qual agradece a nomeação de seu irmão Francisco Machado para o lugar de Provedor da Comarca de Aveiro e lhe dá novas informações relativas à Capitania de Porto Seguro. Porto Seguro, $1^{\circ}$ de julho de 1776 - doc. 9147.

AHU - Projeto Resgate. Carta do Ouvidor da Capitania de Porto Seguro na qual relata os acontecimentos e progressos da sua Capitania no ano anterior. Porto Seguro, 10 de maio de 1770 - doc. 8215.

AHU - Projeto Resgate. Carta do Ouvidor de Porto Seguro José Xavier Machado Monteiro, dirigida ao Rei, na qual relata os progressos daquela capitania durante o ano anterior. Porto Seguro, 10 de maio de 1771 - doc. 8446.

Arquivo Nacional do Rio de Janeiro (ANRJ)

Espaço Ameríndio, Porto Alegre, v. 1, n. 1, p. 42-61, jul./dez. 2007. 
FRANCISCO CANCELA - A presença de não-índios nas vilas de...

ANRJ - Marquês de Lavradio. Carta ao Desembargador Ouvidor de Porto Seguro. Rio de Janeiro, 26 de maio de 1776 - Microfilme: 024.97.

Arquivo Público do Estado da Bahia (APEB)

APEB - Carta de Aplicação da Provisão Real que mandou criar a Vila de Trancoso - Colonial e Provincial, Dossiê sobre aldeamentos e missões indígenas - n. 603.

APEB - Colonial. Auto de audiência geral nesta Vila de Porto Alegre no ano de 1773. Maço: 485-3.

APEB - Decreto por que sua majestade há por bem nomear ao Bacharel Thomé Couceiro de Abreu para hir criar a Ouvidoria de Porto Seguro por tempo de três annos. - Seção de Arquivo Colonial e Provincial, maço 7065, p. 9. 
FRANCISCO CANCELA - A presença de não-índios nas vilas de...

\section{ANEXO 1}

\section{Relação de alguns degradados vindos do Rio de Janeiro para Porto Seguro no ano} de $1776^{6}$.

\begin{tabular}{|c|c|c|c|}
\hline NOME & DATA PARTIDA & CLASSIFICAÇÃO & CRIME \\
\hline Ignácia Nunes & 15 de janeiro & Preta forra & $\begin{array}{l}\text { Curandeira e } \\
\text { homicida }\end{array}$ \\
\hline $\begin{array}{c}\text { Filipe de Morais } \\
\text { Teles }\end{array}$ & 20 de julho & -- & Desordem \\
\hline Ignácia Francisca & 16 de setembro & Parda forra & $\begin{array}{l}\text { Andar vestida em } \\
\text { trajes de homem }\end{array}$ \\
\hline Ana Carvalho & 16 de setembro & Preta forra & Indício de feitiçaria \\
\hline Cypriana Maria & 24 de outubro & -- & $\begin{array}{l}\text { Conduzido muito } \\
\text { mal e desordem }\end{array}$ \\
\hline Ana de Sampaio & 24 de outubro & -- & $\begin{array}{l}\text { Conduzido muito } \\
\text { mal e desordem }\end{array}$ \\
\hline Genoveva de Jesus & 24 de outubro & -- & $\begin{array}{l}\text { Conduzido muito } \\
\text { mal e desordem }\end{array}$ \\
\hline
\end{tabular}

\footnotetext{
${ }^{6}$ Fontes: ANRJ - Marquês de Lavradio. Carta ao desembargador e ouvidor da Comarca de Porto Seguro. Rio de Janeiro, 15 de janeiro de 1776 - Microfilme: 024.97; Carta ao Desembargador de Porto Seguro. Rio de Janeiro, 20 de julho de 1776 - Microfilme: 024.97; Carta ao desembargador ouvidor geral da comarca de Porto Seguro. Rio de Janeiro, 16 de setembro de 1776 - Microfilme: 024.97; Carta ao desembargador e ouvidor da Comarca de Porto Seguro. Rio de Janeiro, 24 de outubro de 1776 Microfilme: 024.97.
} 